\title{
Agonist-Specific Recruitment of Arrestin Isoforms Differentially Modify Delta Opioid Receptor Function
}

\author{
Amynah A. Pradhan, ${ }^{1,2,3}$ Julie Perroy, ${ }^{4,5,6}$ Wendy M. Walwyn, ${ }^{1,2}$ Monique L. Smith, ${ }^{1,2}$ Ana Vicente-Sanchez, ${ }^{3}$ \\ [Daura Segura, ${ }^{3}$ Alia Bana, ${ }^{1,2}$ Brigitte L. Kieffer, ${ }^{7}$ and Christopher J. Evans ${ }^{1,2}$ \\ ${ }^{1}$ Semel Institute for Neuropsychiatry and Human Behavior and ${ }^{2}$ Shirley and Stefan Hatos Center for Neuropharmacology, University of California, Los \\ Angeles, California 90095, ${ }^{3}$ Department of Psychiatry, University of Illinois, Chicago, Illinois 60612, ${ }^{4}$ Centre National de la Recherche Scientifique, Unité \\ Mixte de Recherche-5203, Institut de Génomique Fonctionnelle, Montpellier, F-34094, France, ${ }^{5}$ INSERM, U1191, Montpellier, F-34094, France, ${ }^{6}$ Universités \\ de Montpellier 1 and 2, Unité Mixte de Recherche-5203, Montpellier, F-34094, France, and Douglas Hospital, McGill University, Verdun, Quebec H4H 1R3, \\ Canada
}

Ligand-specific recruitment of arrestins facilitates functional selectivity of G-protein-coupled receptor signaling. Here, we describe agonist-selective recruitment of different arrestin isoforms to the delta opioid receptor in mice. A high-internalizing delta opioid receptor agonist (SNC80) preferentially recruited arrestin 2 and, in arrestin 2 knock-outs (KOs), we observed a significant increase in the potency of SNC80 to inhibit mechanical hyperalgesia and decreased acute tolerance. In contrast, the low-internalizing delta agonists (ARM390, JNJ20788560) preferentially recruited arrestin 3 with unaltered behavioral effects in arrestin 2 KOs. Surprisingly, arrestin 3 KO revealed an acute tolerance to these low-internalizing agonists, an effect never observed in wild-type animals. Furthermore, we examined delta opioid receptor- $\mathrm{Ca}^{2+}$ channel coupling in dorsal root ganglia desensitized by ARM390 and the rate of resensitization was correspondingly decreased in arrestin 3 KOs. Live-cell imaging in HEK293 cells revealed that delta opioid receptors are in pre-engaged complexes with arrestin 3 at the cell membrane and that ARM390 strengthens this membrane interaction. The disruption of these complexes in arrestin $3 \mathrm{KOs}$ likely accounts for the altered responses to low-internalizing agonists. Together, our results show agonist-selective recruitment of arrestin isoforms and reveal a novel endogenous role of arrestin 3 as a facilitator of resensitization and an inhibitor of tolerance mechanisms.

Key words: arrestin; DRG; GPCR; pain; resensitization; tolerance

Significance Statement

Agonists that bind to the same receptor can produce highly distinct signaling events and arrestins are a major mediator of this ligand bias. Here, we demonstrate that delta opioid receptor agonists differentially recruit arrestin isoforms. We found that the high-internalizing agonist SNC80 preferentially recruits arrestin 2 and knock-out (KO) of this protein results in increased efficacy of SNC80. In contrast, low-internalizing agonists (ARM390 and JNJ20788560) preferentially recruit arrestin 3 and, surprisingly, $\mathrm{KO}$ of arrestin 3 produces acute tolerance and impaired receptor resensitization to these agonists. Arrestin 3 is in pre-engaged complexes with the delta opioid receptor at the cell membrane and low-internalizing agonists promote this interaction. This study reveals a novel role for arrestin 3 as a facilitator of receptor resensitization.

\section{Introduction}

G-protein-coupled receptors (GPCRs) regulate diverse biological functions and are the most abundant receptor class in the

\footnotetext{
Received Nov. 16, 2015; revised Jan. 28, 2016; accepted Feb. 11, 2016.

Author contributions: A.A.P., J.P., W.M.W., and C.J.E. designed research; A.A.P., J.P., W.M.W., M.L.S., A.V.-S., L.S., and A.B. performed research; B.L.K. contributed unpublished reagents/analytic tools; A.A.P., J.P., and W.M.W. analyzed data; A.A.P., W.M.W., and C.J.E. wrote the paper.

This work was supported by the National Institute on Drug Abuse-National Institutes of Health (Grant DA05010 to C.J.E. and Grant DA031243 to A.A.P.), the European Research Council under the European Union's Horizon 2020 Research and Innovation Programme (Grant 646788 to J.P.), the Agence Nationale de la Recherche (Grant ANR-13JSV4-0005-01 to J.P.), the Shirley and Stefan Hatos Research Foundation (A.A.P., M.L.S., W.M.W., A.B., B.L.K., and
}

human genome (Lagerström and Schiöth, 2008). These seventransmembrane receptors exist in multiple conformations and ligands can stabilize different active states (Kenakin, 2003). Each receptor conformation can produce distinct receptor-effector

C.J.E.), and the Department of Psychiatry at University of Illinois-Chicago (UIC). We thank the UIC Research Resources Center Imaging Core for help with confocal microscopy.

The authors declare no competing financial interests.

Correspondence should be addressed to Dr. Amynah Pradhan, Department of Psychiatry, University of Illinois at Chicago, 1601 W Taylor St., Chicago IL 60612. E-mail: apradhan@psych.uic.edu.

DOI:10.1523/JNEUROSCI.4124-15.2016

Copyright $\odot 2016$ the authors $\quad 0270-6474 / 16 / 363541-11 \$ 15.00 / 0$ 
complexes that initiate differing signaling and receptor trafficking events (Kenakin, 2012; Reiter et al., 2012). The existence of multiple activation states confer an added degree of complexity to GPCR signaling and allow for highly distinct responses among ligands that act at the same receptor. This concept, referred to as ligand-directed signaling, functional selectivity, or biased agonism (Galandrin et al., 2007; Luttrell, 2014), has important biological and pharmacological implications.

Agonist-selective recruitment of arrestins is a major source of functional selectivity between ligands that bind to the same receptor (Reiter et al., 2012). Arrestins are multifaceted proteins that play an important role in GPCR trafficking and signaling (Shenoy and Lefkowitz, 2011). Agonist binding can produce receptor phosphorylation by G-protein-receptor kinases (GRKs), which in turn results in the binding of arrestins, thus terminating the G-protein-dependent signaling at the membrane (Pierce et al., 2002). Arrestins are also an intracellular scaffold hosting a number of signaling networks, including MAP kinases, c-Src, and Akt-GSK3 (Rajagopal et al., 2010; Shenoy and Lefkowitz, 2011; Reiter et al., 2012). More recently, novel roles of arrestins have emerged as regulators of cytoskeletal proteins (Mittal et al., 2013), protein ubiquitination (Shenoy, 2014), and trafficking of ion channels (Shenoy and Lefkowitz, 2011). Although arrestins have been studied extensively, novel functional aspects continue to be uncovered.

Delta opioid receptor agonists are currently being developed for the treatment of chronic pain and psychiatric disorders (anxiety and depression; Pradhan et al., 2011; van Rijn et al., 2013; Gendron et al., 2015). Similar to other GPCRs, delta opioid receptors are also modulated by arrestins (Lowe et al., 2002; Zhang and Horvath, 2005; Qiu et al., 2007; Raehal and Bohn, 2011). In cellular models, both arrestin 2 ( $\beta$-arrestin 1$)$ and arrestin 3 ( $\beta$ arrestin 2) can mediate delta opioid receptor desensitization and internalization after receptor phosphorylation (Qiu et al., 2007; Hong et al., 2009). However, evidence from a number of in vitro and in vivo studies has revealed biased agonism at the delta opioid receptor (for review, see Pradhan et al., 2012). Live-cell imaging studies using bioluminescence resonance energy transfer (BRET) revealed that, in response to different agonists, the delta opioid receptor can adopt distinct receptor conformations (Audet et al., 2008; Audet et al., 2012; Richard-Lalonde et al., 2013; Charfi et al., 2014; 2015). In addition, delta receptor trafficking is agonist dependent, which has important behavioral consequences (Law et al., 2000; Zhang et al., 2005; Bradbury et al., 2009; Pradhan et al., 2009; Tudashki et al., 2014). Previously, we compared two delta agonists with similar binding and analgesic properties, but high- (SNC80) or low- (ARM390) receptor internalization potencies. After repeated injection, SNC80, but not ARM390, produced acute behavioral tolerance. Upon examination of receptor trafficking, we showed that receptor internalization was directly correlated with receptor function in vivo (Pradhan et al., 2009). We also examined the long-term effects of treating with these different delta agonists and found that distinct forms of chronic tolerance were observed depending on the internalization property of the drug (Pradhan et al., 2010).

The aim of this study was to determine the behavioral significance of delta opioid receptor interactions with arrestin 2 and arrestin 3 and whether this regulation was ligand specific. We show that, in vivo, delta agonists recruit arrestins in a selective manner: binding of a high-internalizing agonist produces preferential interaction between the receptor and arrestin 2 and lowinternalizing agonists preferentially promote arrestin 3-receptor interactions. We also show for the first time that increased arres- tin 3 engagement with the delta opioid receptor can promote receptor resensitization, in marked contrast to its traditional role as a facilitator of desensitization.

\section{Materials and Methods}

Animals. In this study, arrestin 2 and arrestin 3 knock-outs (KOs), DOReGFP knock-in, and arrestin $3 \mathrm{KO} \times$ DOR-eGFP KI mice were used. Arrestin 2 and 3 KOs were generously provided by R. Lefkowitz (Duke University). DOR-eGFP knock-in mice were described previously (Scherrer et al., 2006). Mice were obtained through heterozygous pairings and both males and females were used. Mice, aged 12 weeks on average, were housed in a temperature- and humidity-controlled animal colony on a $12 \mathrm{~h}$ light/dark cycle. Food and water were available ad libitum. All animal experiments were performed according to Association for Assessment and Accreditation of Laboratory Animal Care guidelines as administered by the University of California-Los Angeles Office of Animal Research Oversight and the University of Illinois-Chicago Animal Care Committee.

Inflammatory pain model. All experiments were performed between 8:00 and 16:00. In all cases, mice were habituated to the testing area for 20 min daily for $2 \mathrm{~d}$ before baseline testing. For mechanical responses, the threshold for responses to punctate mechanical stimuli (mechanical hyperalgesia) was tested according to the up-and-down method (Chaplan et al., 1994). In this case, the plantar surface of the hindpaw was stimulated with a series of 8 von Frey filaments (bending force ranging from 0.01 to $2 \mathrm{~g}$ ). A response was defined as a lifting or shaking of the paw upon stimulation. Inflammatory pain was induced by injecting complete Freund's adjuvant (CFA) into the paw. Before the injection of CFA, baseline mechanical responses were determined. Inflammation was induced by injecting $13 \mu \mathrm{l}$ of CFA into the plantar surface of the paw and animals were subsequently tested $72 \mathrm{~h}$ after injection.

Drugs. All drugs were administered in a volume of $10 \mathrm{ml} / \mathrm{kg}$. SNC80 was dissolved in $0.9 \%$ saline, $\mathrm{pH} 5.5$, and injected intraperitoneally. ARM390 and JNJ20788560 were dissolved in $\mathrm{dH} 2 \mathrm{O}$ and administered by oral gavage. Animals were tested $45 \mathrm{~min}$ after treatment with SNC80 and ARM390 and 30 min after treatment with JNJ20788560.

$D R G$ preparation and electrophysiological recording. Delta opioid receptor voltage-dependent $\mathrm{Ca}^{2+}$ channel (VDCC) inhibition was assessed by whole-cell patch-clamp recordings from acutely dissociated L4-L6 DRGs. Adult mice were treated with CFA and, after $72 \mathrm{~h}$, they were killed and the ipsilateral DRGs collected in complete saline solution (CSS) containing the following (in $\mathrm{mm}$ ): $137 \mathrm{NaCl}, 5.3 \mathrm{KCl}, 1 \mathrm{MgCl}_{2}, 25$ sorbitol, $10 \mathrm{HEPES}$, and $3 \mathrm{CaCl}_{2}$ and incubated in collagenase [1.25 $\mathrm{U}$ of Liberase TH (high thermolysin); Roche], $250 \mathrm{~nm}$ EDTA for $20 \mathrm{~min}$ at $32^{\circ} \mathrm{C}$, transferred to fresh CSS containing collagenase $[1.25 \mathrm{U}$ of Liberase TM (medium thermolysin); Roche] with $250 \mathrm{~nm}$ EDTA and $0.25 \mathrm{U}$ of papain (Roche), and incubated for $10 \mathrm{~min}$ at $32^{\circ} \mathrm{C}$. After 2 washes and physical trituration through a series of graded Pasteur pipettes, the cells were spun (1000 rpm, $3 \mathrm{~min}$ ) and plated in Neurobasal/B27/Glumax/ Antibiotic/Antimycotic (Life Technologies) supplemented with 10 ng/ml NGF (Life Technologies). All recordings were performed within $6 \mathrm{~h}$ after plating. For each recording, culture medium was replaced by an external solution that contained the following (in mM): 130 TEA-Cl, 10 $\mathrm{CaCl}_{2}, 5$ HEPES, $25 \mathrm{D}$-glucose, and $2.5 \times 10^{-4}$ tetrodotoxin, $\mathrm{pH} 7.2$. Recording electrodes contained the following (in $\mathrm{mm}$ ): $105 \mathrm{CsCl}, 40$ HEPES, 5 D-glucose, $2.5 \mathrm{MgCl}_{2}, 10$ EGTA, $2 \mathrm{Mg}^{2+}$-ATP, and $0.5 \mathrm{Na}^{+}$GTP, $\mathrm{pH}$ 7.2. The potential difference between the open electrode and the bath ground was zeroed before establishing a $\geq 1 G \Omega$ resistance seal. No compensation was made for the cancellation of liquid junction potential. $\mathrm{Ca}^{2+}$ currents were activated by depolarizing neurons from -80 to $10 \mathrm{mV}$ for $100 \mathrm{~ms}$ at $10 \mathrm{~s}$ intervals. Currents were low-pass filtered at 2 $\mathrm{kHz}$ and digitized (Digidata; Molecular Devices) at $10 \mathrm{kHz}$. Leak currents were nulled using the $\mathrm{P} / 4$ subtraction method. DRG neurons were rapidly and continuously superfused $(5 \mathrm{ml} / \mathrm{min})$ with external solution. SNC80 $(1 \mu \mathrm{M})$ was diluted into external solution on the day of the experiment and applied through the perfusion system. Experiments were performed at room temperature $\left(22-24^{\circ} \mathrm{C}\right)$. Mean $\mathrm{Ca}^{2+}$ current amplitudes were measured (pCLAMP 9.0; Molecular Devices) between 5 and $10 \mathrm{~ms}$ 
A

$45 \min$

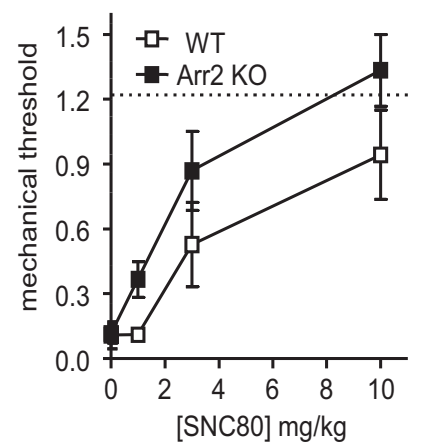

C

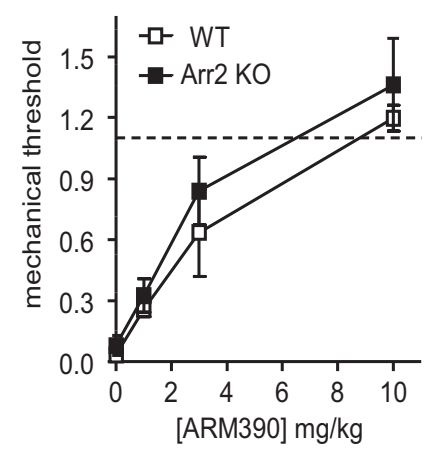

E

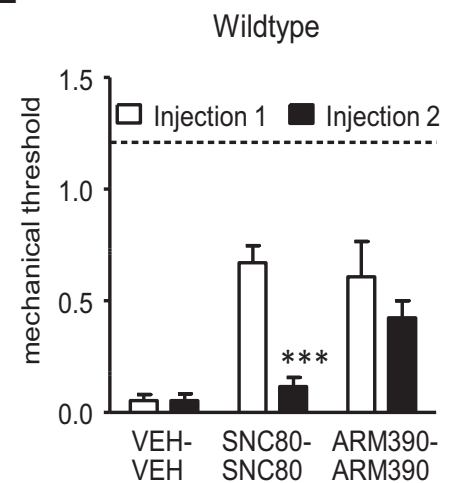

B

$4 \mathrm{hr}$

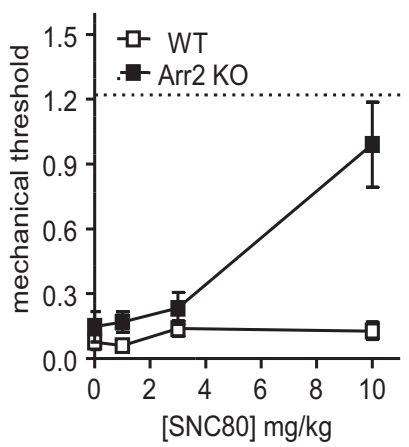

D

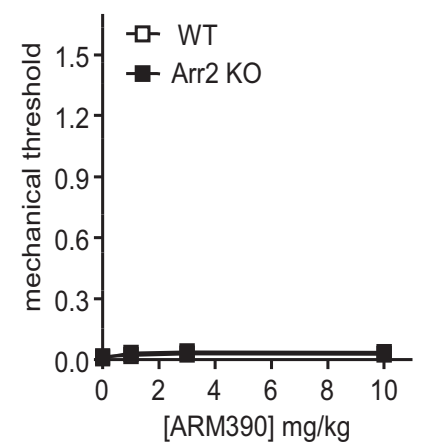

$\mathbf{F}$

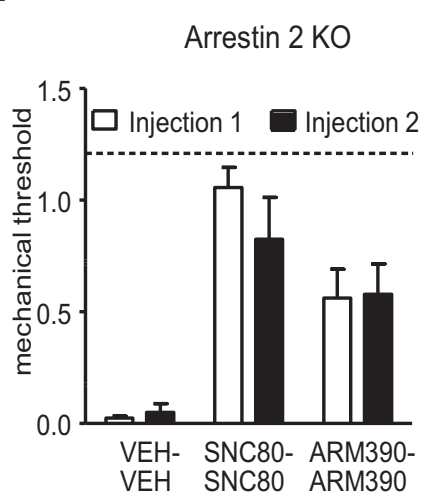

Figure 1. SNC80, but not ARM390, has increased potency and duration of action, and decreased acute tolerance in arrestin $2 \mathrm{KO}$ mice. In a CFA model of inflammatory pain, we performed a dose and time response to SNC80 and ARM390. The anti-hyperalgesic effect of SNC80 (IP; $\boldsymbol{A})$ was significantly enhanced in arrestin $2 \mathrm{K0}$ mice $(p<0.05)$, and was longer lasting $(\boldsymbol{B})(p<0.001) . \boldsymbol{C}, \boldsymbol{D}$, ARM390 (P0) was equipotent in arrestin 2 WT and KO mice (C) and anti-hyperalgesic effects were lost $4 \mathrm{~h}$ after administration regardless of genotype $(\boldsymbol{D})$. For acute tolerance experiments, Injection 1 represents mechanical responses in WT $(\boldsymbol{E})$ and arrestin 2 KO $(\boldsymbol{F})$ mice acutely treated with vehicle (control), SNC80 (3 mg/kg), or ARM390 (3 mg/kg). For Injection 2, animals were rechallenged with the same drugs and doses $4 \mathrm{~h}$ after Injection 1. Dashed lines represent baseline mechanical responses pre-CFA. For dose/time responses, two-way ANOVA was used ( $n=5-7$ mice/group). For acute tolerance, paired $t$ tests with Bonferroni correction were used ( ${ }^{* *} p<0.001 ; n=7-10$ mice/group). SNC80 is more effective in arrestin 2 K0 mice.

after initiating the depolarizing step. Mean current amplitudes were then plotted against time. Stable recordings were fitted by a linear function to compare, by extrapolation, control current amplitude with the current amplitude recorded in the presence of opioid receptor agonists.

Confocal microscopy. To determine the subcellular distribution of DOR-eGFP after agonist stimulation, mice were anesthetized with pentobarbital (somnosol, $150 \mathrm{mg} / \mathrm{kg}$ ) and intracardially perfused with $10 \mathrm{ml}$ of $0.1 \mathrm{M}$ phosphate buffer (PB), followed by $30 \mathrm{ml}$ of $4 \%$ paraformaldehyde in $0.1 \mathrm{M} P B, \mathrm{pH}$ 7.4. Dorsal root ganglia (DRG) were then postfixed for $2 \mathrm{~h}$ at $4^{\circ} \mathrm{C}$ in the fixative solution. The tissue was then cryoprotected at $4^{\circ} \mathrm{C}$ in a $30 \%$ sucrose, $0.1 \mathrm{M} \mathrm{PB}$ solution until the tissue sank. Sections were cut at $14 \mu \mathrm{m}$ in a cryostat and mounted on charged glass slides. Sections were immunostained for GFP. Briefly, tissue was blocked with $5 \%$ normal donkey serum $/ 0.3 \%$ Triton X-100/0.1 м PB for 2 h. Sections were incubated overnight with rabbit anti-GFP antibody (1:1000; Life Sciences) at room temperature. Sections were washed and incubated with a donkey anti-rabbit secondary antibody conjugated to Alexa Fluor 488 (1: 1000; Life Sciences) for $2 \mathrm{~h}$ at room temperature and then washed in PBS and coverslipped. All samples were observed under a Zeiss LSM 710 confocal microscope $(63 \times$ objective and numerical aperture of 1.2) and Zen (Zeiss) software was used for image acquisition. Quantification of cell surface mean fluorescence intensity was determined using ImageJ software. Nuclear fluorescence defined the background level and was subtracted from the cell membrane fluorescence measures (for further details, see Scherrer et al., 2006). In total, three to five DRGs/mouse were analyzed and there were five to nine mice/group.

BRET analysis. For BRET in cell population, cells were counted by measuring protein concentration (Dc protein assay kit; Bio-Rad). For total fluorescence and luminescence measurements, cells were dispersed in 96 well plates with clear bottoms (Costar) at a density of 100,000 cells per well. Total fluorescence of the cells was measured in the Mithras LB 940 instrument (Berthold Technologies) using an excitation filter at $485 \mathrm{~nm}$ and an emission filter at $530 \mathrm{~nm}$. The light emitted at $530 \mathrm{~nm}$ upon light excitation at $485 \mathrm{~nm}$ (Fluo) is indicative of the amount of YFP-tagged proteins. Cells were then incubated with Deep Blue C coelenterazine ( $5 \mathrm{~mm}$ ) to measure the total luminescence using the Mithras. The light emitted at $400 \mathrm{~nm}$ in presence of Deep Blue C (Lumi) is indicative of the amount of Rluc-tagged proteins. For BRET measurements, cells coexpressing $\delta \mathrm{OR}-$ Rluc and Arr2-YFP or Arr3-YFP constructs were distributed in white 96-well microplates (Corning) at a density of 100000 cells per well. BRET was initiated by adding $5 \mathrm{~mm}$ coelenterazine $\mathrm{H}$ and the ratio of the light emitted by YFP $(510-550 \mathrm{~nm})$ to the light emitted by the Rluc (460-500 nm) was measured using a fluorimeter (Mithras; Berthold Technologies). Values were corrected by subtracting the background ratio detected when the Rluc construct was expressed alone.

Single-cell BRET imaging in HEK293cells to study the subcellular localization of the interaction between arrestins and $\delta$ OR-Rluc 8 were performed according to previous protocols (Coulon et al., 2008; Perroy, 2010). Briefly, images were obtained using a Plan-Apochromat $63 \times / 1.40$ oil M27 objective at room temperature. Transfected cells were first identified using a monochromatic light and appropriate filter to excite YFP (exciter HQ480/40, emitter HQ525/50; Chroma) or mOrange (exciter HQ540/ 40, emitter HQ600/50; Chroma). The light source was then switched off until the end of the experiment. Coelenterazine $\mathrm{H}(20 \mu \mathrm{M})$ was applied for $5 \mathrm{~min}$ before acquisition with MetaMorph software (Molecular Devices). BRET images were collected every $45 \mathrm{~s}$ by sequential acquisitions from the $480 \mathrm{~nm}, 535$ and $562 \mathrm{~nm}$ channels of $15 \mathrm{~s}$ each, using the evolve 
A

SNC80

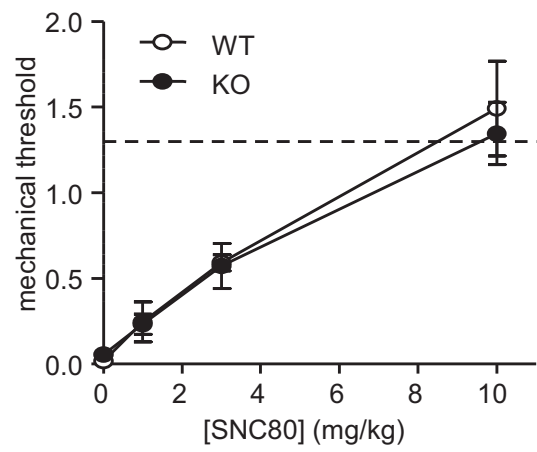

C

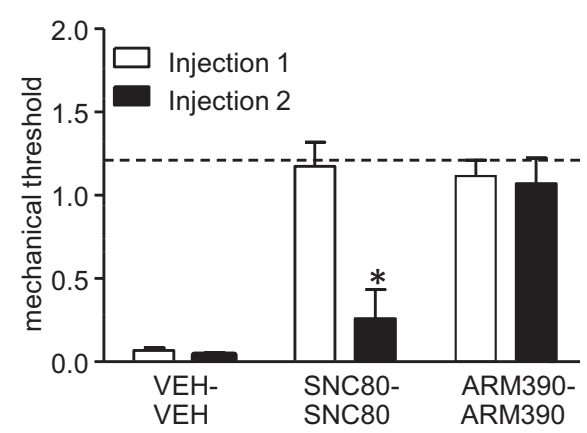

E

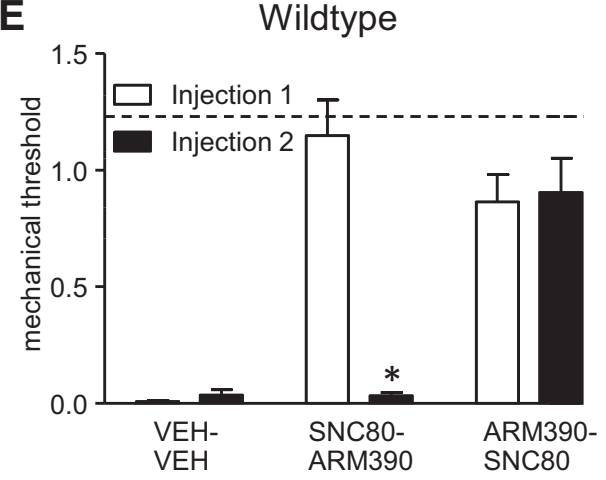

B

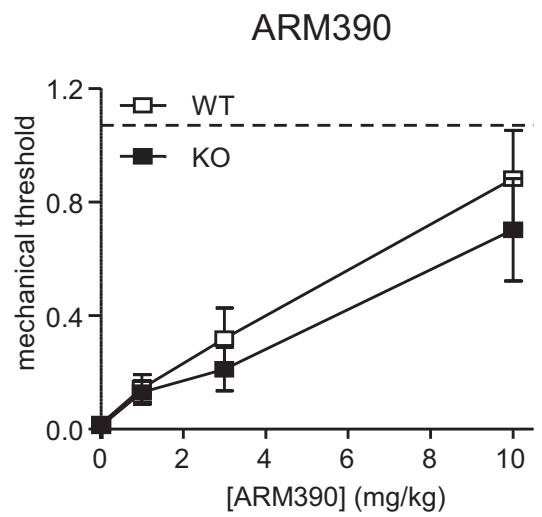

D

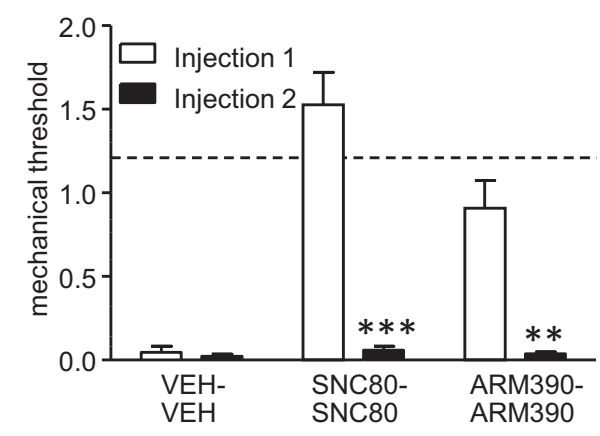

F

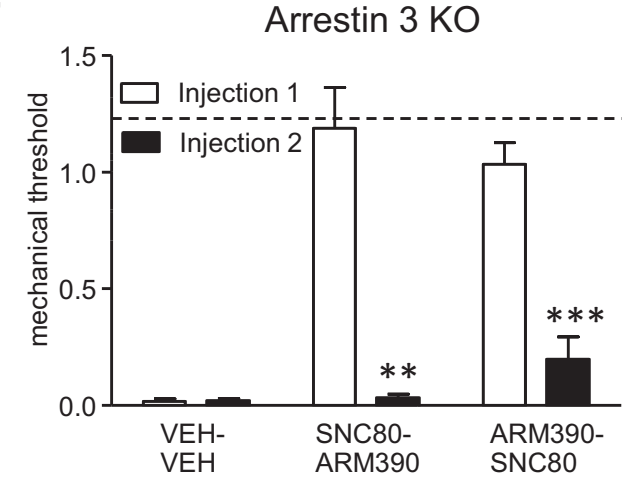

Figure 2. Acute tolerance and cross-tolerance to ARM390 is gained in arrestin $3 \mathrm{KO}$ mice. Mechanical responses were determined in the CFA model of inflammatory pain. Arrestin 3 WT and KO animals were treated with differing doses of SNC 80 ( $A$ ) or ARM390 ( $\boldsymbol{B}$ ) and tested 45 min after drug administration ( $n=5-7 /$ group). K0 of arrestin 3 does not change potency of either delta agonist. For acute tolerance and cross-tolerance experiments $(\boldsymbol{C}-\boldsymbol{F})$, Injection 1 and Injection 2 were $4 \mathrm{~h}$ apart. WT and arrestin $3 \mathrm{KO}$ mice were treated with vehicle (control), SNC80 (10 mg/kg), or ARM390 $(10 \mathrm{mg} / \mathrm{kg})$ and then rechallenged $4 \mathrm{~h}$ later with the same drug $(\boldsymbol{C}, \boldsymbol{D})$ or the other $\operatorname{drug}(\boldsymbol{E}, \boldsymbol{F})$. Dashed lines represent baseline mechanical responses pre-CFA. ${ }^{*} p<0.05,{ }^{* *} p<0.01,{ }^{* * *} p<0.001$, paired $t$ test with Bonferroni correction ( $n=4-10$ mice/group). In the absence of arrestin 3, ARM390 produces acute and cross-tolerance at the delta opioid receptor.

camera from Photometrics. Drugs were added $3 \mathrm{~min}$ after the first acquisition. Sequential acquisitions were performed at $5 \mathrm{MHZ}$ (Gain 3950 , bining 1) with emission filters D480/60 nm, HQ535/50 nm, and HQ585/40 nm to select em480 (Rluc), em535 (YFP), and em562 (mOrange) wavelengths, respectively. An exclusive threshold was applied on the Em 480 image from 0 to 4000 counts to exclude these nonreliable weak values. The pixel-by-pixel $535 \mathrm{~nm} / 480 \mathrm{~nm}$ ratios, BRET1 images were calculated by dividing the absolute blue or yellow intensities per pixel of images obtained at $535 \mathrm{~nm}$ over $480 \mathrm{~nm}$. The pixel-by-pixel $562 \mathrm{~nm} / 480 \mathrm{~nm}$ ratios, BRET3 images, were also obtained by dividing the absolute blue or orange intensities per pixel of images obtained at $562 \mathrm{~nm}$ over $480 \mathrm{~nm}$. These numerical ratios (comprising between 0 and 1 for BRET 1 and between 0 and 0.3 for BRET3) were translated and visualized with a continuous 256 pseudocolor look-up table as displayed in the figures. The average intensity of the $535 \mathrm{~nm} / 480$ and $562 \mathrm{~nm} / 480 \mathrm{~nm}$ fluorescence ratios were determined in the square region of $20 \times 20$ pixels drawn on the subcellular compartment of interest using ImageJ software. The mean \pm SEM obtained from three to six cells and seven square regions per cell in the same subcellular compartment and in identical stimulating conditions were averaged.

Statistical analysis. Data are expressed as mean \pm SEM. All graphs were produced in GraphPad Prism version 4 and all statistical analysis was performed in SigmaStat software. For pain experiments, two-way repeated-measures ANOVAs were performed or, where cited, $t$ tests with Bonferroni correction were used. For electrophysiological and BRET experiments, one-way ANOVA was performed. For all ANOVA analyses, a Holm-Sidak post hoc analysis was performed when appropriate.

\section{Results}

We compared delta opioid receptor specific agonists with similar binding and anti-hyperalgesic properties, but high (SNC80) or 
A

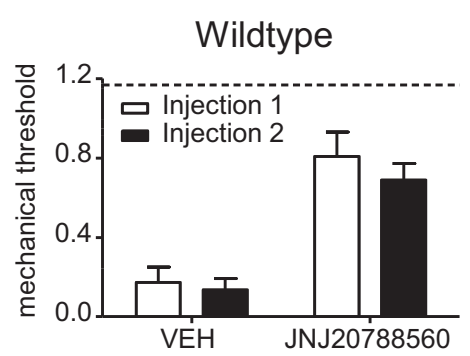

C

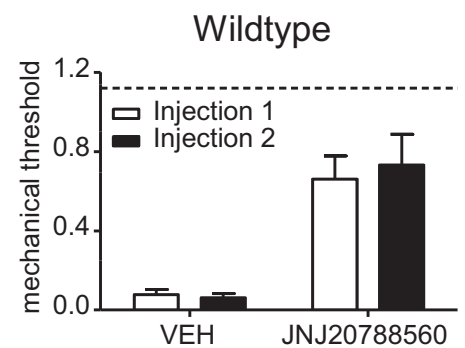

B

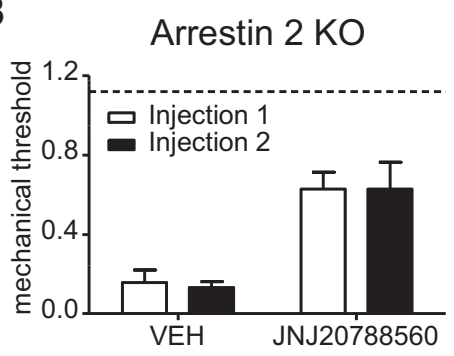

D

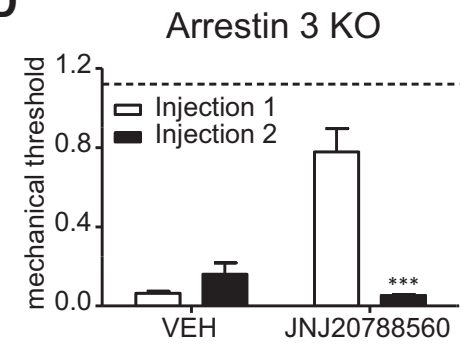

Figure 3. The low-internalizing agonist JNJ20788560 shows similar properties to ARM390 in arrestin 2 and 3 KO mice. Mechanical responses were determined in the CFA model of inflammatory pain. Arrestin 2 WT $(\boldsymbol{A})$, arrestin 2 KO $(\boldsymbol{B})$, arrestin 3 WT $(\boldsymbol{C})$, and arrestin 3 KO (D) mice were tested with vehicle (VEH) or JNJ20788560 (100 mg/kg, p.o.) and then rechallenged with the same compound $4 \mathrm{~h}$ later. Dashed lines represent baseline mechanical responses pre-CFA. ${ }^{* *} p<0.001$, two-way repeated-measures ANOVA ( $n=7-15$ mice/group). KO of arrestin 3 produces acute behavioral tolerance to low-internalizing delta agonists.

low (ARM390 or JNJ20788560) internalization potencies (Pradhan et al., 2009; Pradhan et al., 2010). We characterized the ligand-specific effects in both arrestin 2 and arrestin $3 \mathrm{KO}$ mice. The CFA mouse model of inflammatory pain was used throughout the in vivo experiments.

\section{Acute behavioral tolerance to SNC80, but not ARM390, is attenuated in arrestin $2 \mathrm{KO}$ mice}

We initially tested the effect of arrestin $2 \mathrm{KO}$ on the anti-hyperalgesic effect of delta opioid receptor agonists in the CFA inflammatory pain model. We performed a dose and time response to SNC80 and ARM390 in arrestin 2 wild-type (WT) and KO mice. CFA was injected into the hindpaw and, $72 \mathrm{~h}$ later, mice were injected with varying doses of SNC80 and ARM390 and tested $45 \mathrm{~min}$ (Fig. 1 A,C) and $4 \mathrm{~h}($ Fig. $1 B, D)$ after injection. SNC80 was significantly more potent in arrestin $2 \mathrm{KO}$ mice (Fig. $1 A$ ) and, at the highest dose, its pain-relieving effects were longer lasting (Fig. $1 B$ ). In contrast, ARM390 had similar potency (Fig. 1C) and duration of action in arrestin $2 \mathrm{WT}$ and $\mathrm{KO}$ animals (Fig. 1D).

We showed previously that repeated injection of the highinternalizing agonist SNC80 produces acute behavioral tolerance, whereas the low-internalizing agonist ARM390 does not (Pradhan et al., 2009). Here, we tested arrestin 2 WT and KO within the same paradigm. To avoid the increased duration of action of the high dose of SNC80, we tested these animals with a submaximal $3 \mathrm{mg} / \mathrm{kg}$ dose. CFA was injected into the mouse paw and severe mechanical hypersensitivity was observed $72 \mathrm{~h}$ later (Fig. 1 E, F, dashed line vs vehicle controls). In WT and arrestin 2 KO mice, an initial injection of SNC80 and ARM390 attenuated this hyperalgesia (Fig. 1E, Injection 1). As reported previously, a second injection of SNC80 was ineffective in WT animals (Fig. $1 E$, Injection 2); however, this acute behavioral tolerance was not observed in arrestin $2 \mathrm{KOs}$ (Fig. 1F, Injection 2). A second injection of ARM390 was equally effective in both WT and KO mice. These results indicate that arrestin 2 disrupts acute tolerance to high-internalizing, but not low-internalizing, agonists.
Acute behavioral tolerance to ARM390 is enhanced in arrestin $3 \mathrm{KO}$ mice

Arrestin 3 has been shown previously to regulate opioid receptor trafficking in a number of cellular model systems (Qiu et al., 2007; Hong et al., 2009). We examined the in vivo effect of arrestin 3 on the regulation of delta opioid receptors after agonist binding. An initial dose-response curve showed that there was no significant difference between arrestin 3 WT and $\mathrm{KO}$ mice to either SNC80 (Fig. 2A) or ARM390 (Fig. 2B). We performed an acute tolerance experiment and an initial injection of SNC80 and ARM390 was effective at reducing CFA-induced hyperalgesia (Fig. 2C,D, Injection 1). A second injection of SNC80 produced acute behavioral tolerance in both arrestin 3 WT and $\mathrm{KO}$ mice (Fig. 2C,D, Injection 2), which is consistent with the notion that SNC80-bound delta opioid receptors preferentially recruit arrestin 2. Surprisingly, arrestin $3 \mathrm{KOs}$ acquired acute behavioral tolerance to the low-internalizing agonist ARM390 (Fig. 2D, Injection 2). Acute tolerance to ARM390 is not observed in WT animals (Figs. 1E, 2C, Injection 2, and Pradhan et al., 2009; Pradhan et al., 2010) and the low-internalizing properties of ARM390 would suggest that arrestins would not be recruited after its binding. To confirm that this tolerance was due to changes at the delta opioid receptor, we did a cross-tolerance study in which the animals initially received SNC80 or ARM390 and were then rechallenged $4 \mathrm{~h}$ later with the other drug. An initial injection of SNC80 produced cross-tolerance to ARM390 in both WT and arrestin $3 \mathrm{KO}$ mice (Fig. 2E,F). In contrast, injection of ARM390 only produced cross-tolerance in arrestin 3 $\mathrm{KO}$ mice, an effect that was not observed in WT controls (Fig. $2 E, F$, Injection 2). Therefore, $\mathrm{KO}$ of arrestin 3 results in a gain of acute tolerance to the low-internalizing agonist ARM390 and implicates arrestin 3 as being protective against delta opioid receptor tolerance mechanisms after binding to low-internalizing, but not high-internalizing, agonists.

We also determined the time to recover from the acute tolerance induced by ARM390 in arrestin 3 KOs. We found that a second injection $24 \mathrm{~h}$ after the first injection of ARM390 showed a pain-relieving effect of this agonist comparable to Injection 1 (Injection 1: $0.987 \pm 0.097$ vs Injection 224 h later: $1.27 \pm 0.32$ ). How this recovery occurs is currently unknown, but possibilities include de novo receptor synthesis, trafficking of receptor from intracellular stores, or an unknown recycling/resensitization process.

To confirm that ARM390 was not the only delta agonist that resulted in this unique interaction with arrestin 3, we tested another low-internalizing agonist, JNJ20788560 ((Codd et al., 2009); Fig. 3). Similar to ARM390, KO of arrestin 2 did not affect acute tolerance (Fig. $3 \mathrm{~A}, \mathrm{~B}$ ); however, complete behavioral acute tolerance to JNJ20788560 was observed in arrestin $3 \mathrm{KO}$ mice (Fig. 3C,D). The interaction of arrestin 3 to protect against acute tolerance at the delta opioid receptor is therefore not unique to ARM390 and also appears to be a property of other lowinternalizing delta agonists. 

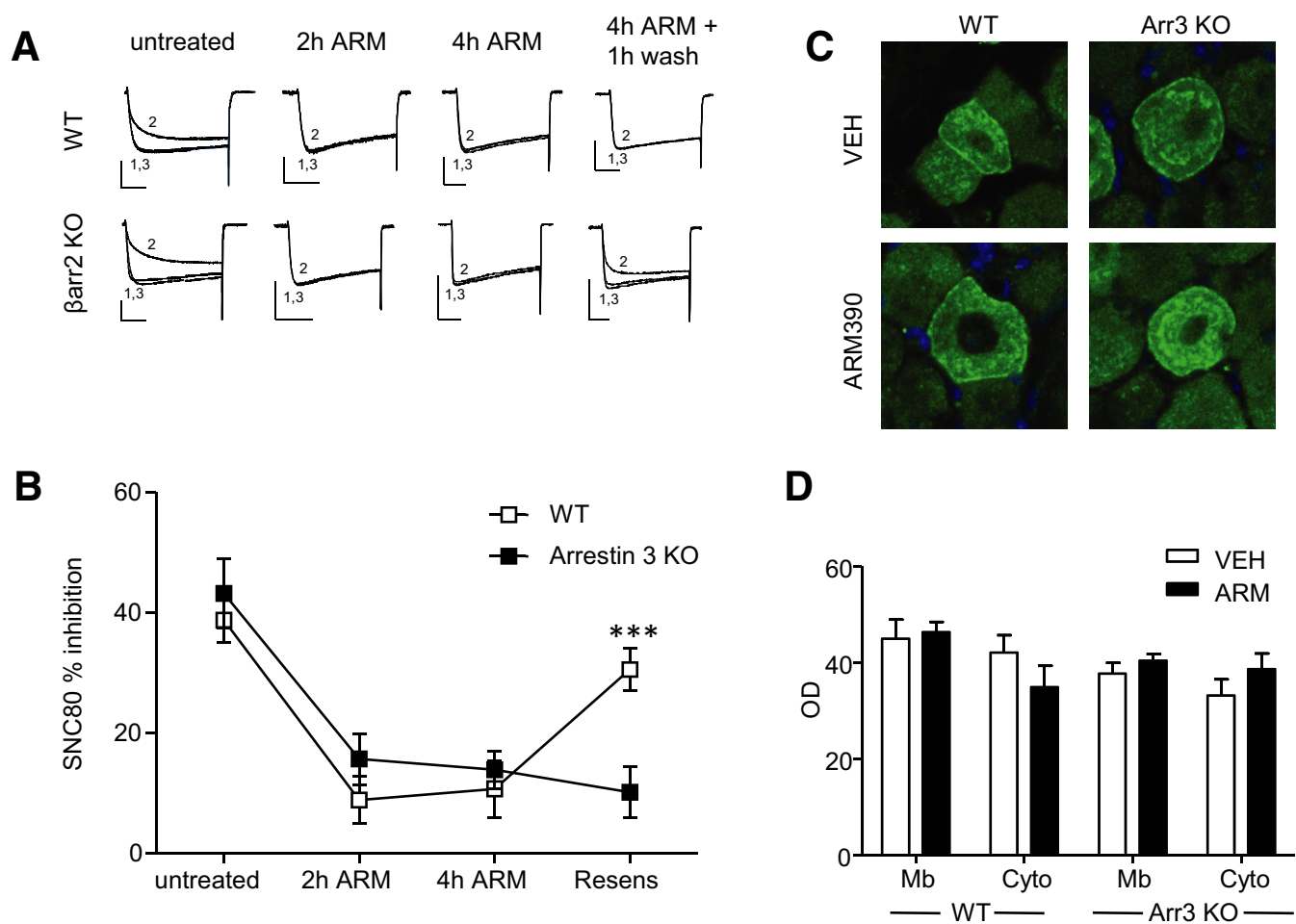

Figure 4. Arrestin $3 \mathrm{KO}$ attenuates the rate of resensitization of delta opioid receptor function after ARM390, but does not alter receptor trafficking. $A$, Rpresentative curves and mean SNC $80 \%$ inhibition from patch-clamp analysis of $\mathrm{Ca}^{2+}$ channel inhibition in DRGs from arrestin 3 WT and KO mice. Exemplar currents show VDCCs before (1), during (2), and after (3) SNC80 (1 $\mu$ M) application. $B$, Desensitization, assessed by a $1 \mu \mathrm{m}$ test dose of SNC80, occurred equally in both WT and KO DRGs after 2 and $4 \mathrm{~h}$ of ARM390 (100 nM) pre-incubation. Thereafter, SNC80 inhibition of VDCCs recovered after $1 \mathrm{~h}$ of washout in WT, but not in DRGs from arrestin $3 \mathrm{KO}$ mice ${ }^{* * *} p<0.001$, one-way ANOVA with Holm-Sidak post hoc analysis ( $n=7-12$ cells). In addition, DOR-eGFP reporter mice were crossed with arrestin 3 WT and KOs. Mice were treated with vehicle or ARM390 (10 mg/kg, p.o.) and DRGs were collected $4 \mathrm{~h}$ later. C, DRGs were analyzed by confocal microscopy and representative images are shown. $\boldsymbol{D}$, Mean cell membrane (Mb) and cytosolic (Cyto) fluorescence was quantified in three to five neurons from each mouse, with five to nine mice/group. Delta opioid receptors in arrestin $3 \mathrm{KO}$ s showed decreased resensitization after ARM390 that was not due to enhanced receptor internalization.

\section{Arrestin 3 deletion impairs resensitization of delta opioid receptor function in DRG}

We focused the next experiments on characterizing the acute behavioral tolerance to low-internalizing agonists observed in arrestin 3 KOs. We started by examining the modulation of $\mathrm{Ca}^{2+}$ channels by delta opioid receptors in DRG. DRGs are the firstorder neurons in the pain transmission pathway and the painrelieving effects of delta agonists within peripheral pain models are mediated by a subset of these neurons (Gavériaux-Ruff et al., 2011). We assessed delta opioid receptor inhibition of $\mathrm{Ca}^{2+}$ currents as a measure of receptor function (Walwyn et al., 2005). The conditions used in these experiments were chosen specifically to reflect our in vivo acute tolerance paradigm. Adult arrestin $3 \mathrm{WT}$ and $\mathrm{KO}$ mice were injected with CFA and L4-L6 ipsilateral DRGs were collected $72 \mathrm{~h}$ later and acutely dissociated. We assessed both the rates of desensitization and resensitization of delta opioid receptor inhibition of VDCCs by a $1 \mu \mathrm{M}$ SNC80 challenge. Desensitization was defined as loss of delta opioid receptor inhibition of VDCCs after 2 or $4 \mathrm{~h}$ application of ARM390; and resensitization as the recovery of this inhibition after a $1 \mathrm{~h}$ washout. We observed full VDCC desensitization, as defined by reduced SNC80-VDCC inhibition, by $4 \mathrm{~h}$ in both arrestin $3 \mathrm{WT}$ and $\mathrm{KO}$ mice (Fig. $4 A, B$ ). Resensitization, as defined by a recovery of SNC80-VDCC inhibition after $1 \mathrm{~h}$ of washout, occurred in WT, but not arrestin $3 \mathrm{KO}$, DRGs (Fig. $4 A, B$ ). These results indicate that arrestin 3 endogenously facilitates resensitization of the delta opioid receptor after ARM390-induced desensitization.

We also determined whether ARM390 induced internalization in arrestin $3 \mathrm{KO}$ mice, which might explain the acquired acute tolerance in these animals. We crossed the reporter DOReGFP knock-in mice (Scherrer et al., 2006) with arrestin $3 \mathrm{KO}$ mice. Mice were injected with CFA and, $72 \mathrm{~h}$ later, treated with ARM390; receptor localization was determined $4 \mathrm{~h}$ after drug administration. ARM390 did not appear to cause significant internalization of DOR-eGFP in DRGs from arrestin $3 \mathrm{KO}$ mice (Fig. 4C,D). We conclude that it is unlikely that the behavioral desensitization induced by ARM390 in arrestin $3 \mathrm{KO}$ is due to receptor sequestration.

Arrestin 3 and delta opioid receptors are pre-engaged at the cell surface and ARM390 binding increases this interaction Our in vivo behavioral and electrophysiological results suggest that agonist bias at the delta opioid receptor can result from differential recruitment of arrestin isoforms. To examine the basal and agonist-induced interactions between delta opioid receptors and arrestin 2 or 3 directly, we used BRET imaging in transected HEK293 cells. We used this assay to examine the protein-protein interactions that occur basally and soon after agonist activation of the receptor. Initially, we examined the basal interaction between delta opioid receptor and each arrestin alone in the absence of agonist. The $\mathrm{C}$ terminus of the delta opioid receptor was fused to the energy donor Renilla luciferase ( $\delta \mathrm{OR}$ Rluc8) and each arrestin was fused to the energy acceptor YFP (Arr2-YFP, Arr3-YFP). Under conditions in which $\delta$ OR-Rluc8 expression levels were kept constant, BRET signal increased hyperbolically as a function of Arr3-YFP, but not Arr2-YFP, expression level (Fig. 5A). Saturation of the BRET signal when all of the donor was linked to the acceptor indicated a specific basal inter- 
A

- BRET Arrb2

$\triangle$ BRET Arrb3

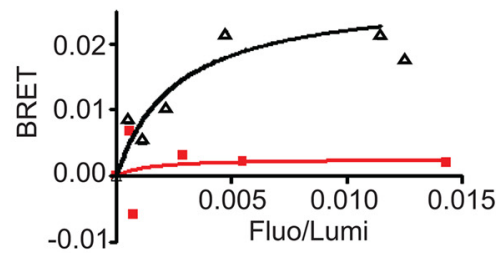

B ARM390 : $\delta$ OR-Rluc8 + Arr2-YFP OR Arr3-mOrange
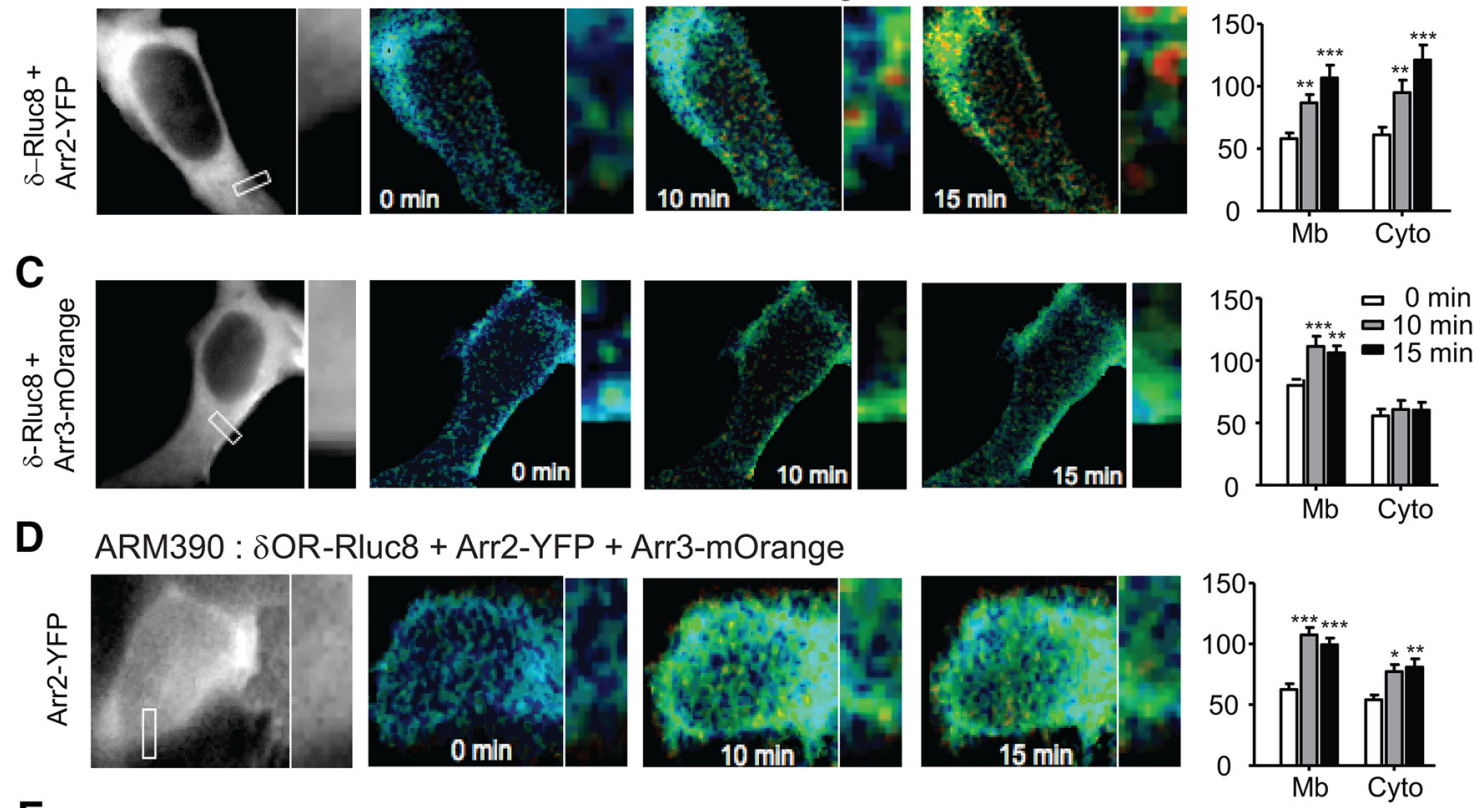

\section{E}
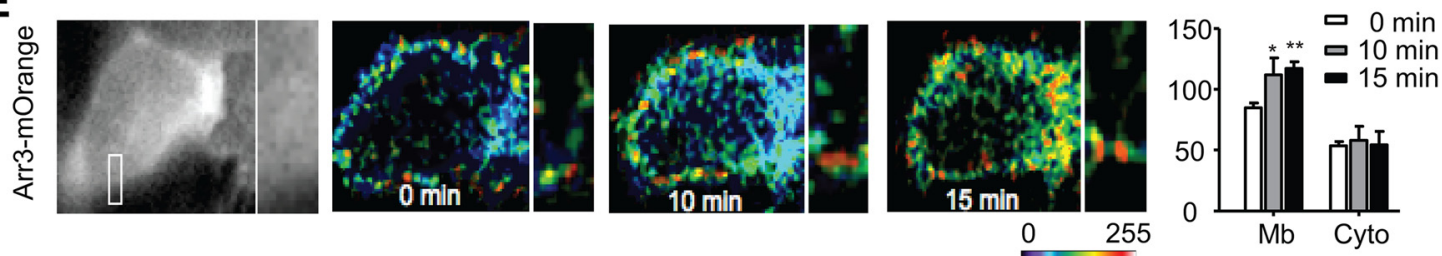

Figure 5. Arrestin 3 and delta opioid receptors are pre-engaged on the cell membrane and ARM 390 increases this association. A, Basal BRET signal between $\delta 0 R$-Rluc and Arr2-YFP or Arr3-YFP. HEK293 cells were cotransfected with a constant concentration of $\delta 0 R$-Rluc and increasing concentrations of Arr2-YFP or Arr3-YFP plasmids. The data shown are representatives of five independent experiments. The curves were fitted using a nonlinear regression equation assuming a single binding site. BRET is expressed as a function of $\delta 0 R$ expression for a constant amount of arrestin and shows increased basal interaction at the cell membrane between $\delta 0$ R-Rluc 8 and Arr3-YFP, which is not observed between $\delta 0 R$-Rlub8 and Arr2-YFP. B-E, To determine the effect of ARM390 on delta opioid receptor-arrestin interactions, HEK293 cells were transfected with $\delta 0$ R-Rluc8 and Arr2-YFP (B), $\delta 0$ R-Rluc 8 and Arr3-m0range $(\boldsymbol{C})$, or $\delta 0 R-R l u c 8$, Arr2-YFP, and Arr3-m0range (D, E). For the three partners-BRET experiment, $\boldsymbol{D}$ shows representative images from the Arr2-YFP channel and $\boldsymbol{E}$ those from the Arr3-mOrange channel. Cells were incubated with ARM390 (100 nM) and mean BRET intensity was quantified for the cell membrane (Mb) and cytosol (Cyto) at 0, 10, and 15 min after ARM390 administration. ${ }^{*} p<0.05$, ${ }^{* *} p<0.01$, and ${ }^{* * *} p<0.001$, one-way ANOVA with Holm-Sidak post hoc analysis ( $n=3-6$ cells and 7 square regions per subcellular compartment). Delta opioid receptors are pre-engaged with Arr3 at the cell membrane and this interaction is strengthened after ARM390 binding.

action between $\delta$ OR-Rluc8 and Arr3-YFP proteins in absence of ligand, an effect not observed between $\delta$ OR-Rluc8 and Arr2-YFP.

We next examined the effect of delta agonists on delta opioid receptor-arrestin interactions. In this case, the $\mathrm{C}$ termini of arrestin 2 and arrestin 3 were fused to the energy acceptors YFP (Arr2-YFP) and mOrange (Arr3-mOrange), respectively. We initially performed BRET analysis by expressing $\delta \mathrm{OR}$-Rluc8 with either Arr2-YFP or Arr3-mOrange separately. To determine the subcellular interactions between these molecules, we quantified cell membrane and cytosolic interactions separately. We used a dose of ARM390 $(0.1 \mu \mathrm{M})$, which was not shown previously to induce internalization in primary cell cultures (Pradhan et al.,
2009). Application of ARM390 produced a time-dependent increase in BRET signal between $\delta$ OR-Rluc8 and Arr2-YFP at both the membrane and cytosol (Fig. 5B). These results indicate that arrestin 2 induces intracellular complexes with the delta opioid receptor after ARM390 binding in the absence of arrestin 3. In contrast, when we examined BRET between $\delta$ OR-Rluc 8 and Arr3-mOrange, ARM390 produced a significant enhancement of BRET signal at the plasma membrane specifically (Fig. $5 C, \mathrm{Mb}$ ), but did not appear to cause detectable intracellular interactions (Fig. 5C, Cyto).

We next coexpressed $\delta$ OR-Rluc8 with both Arr2-YFP and Arr3-mOrange. After the addition of ARM390, 8 OR-Rluc8 and Arr2-YFP interactions were increased at the cell membrane, al- 
A
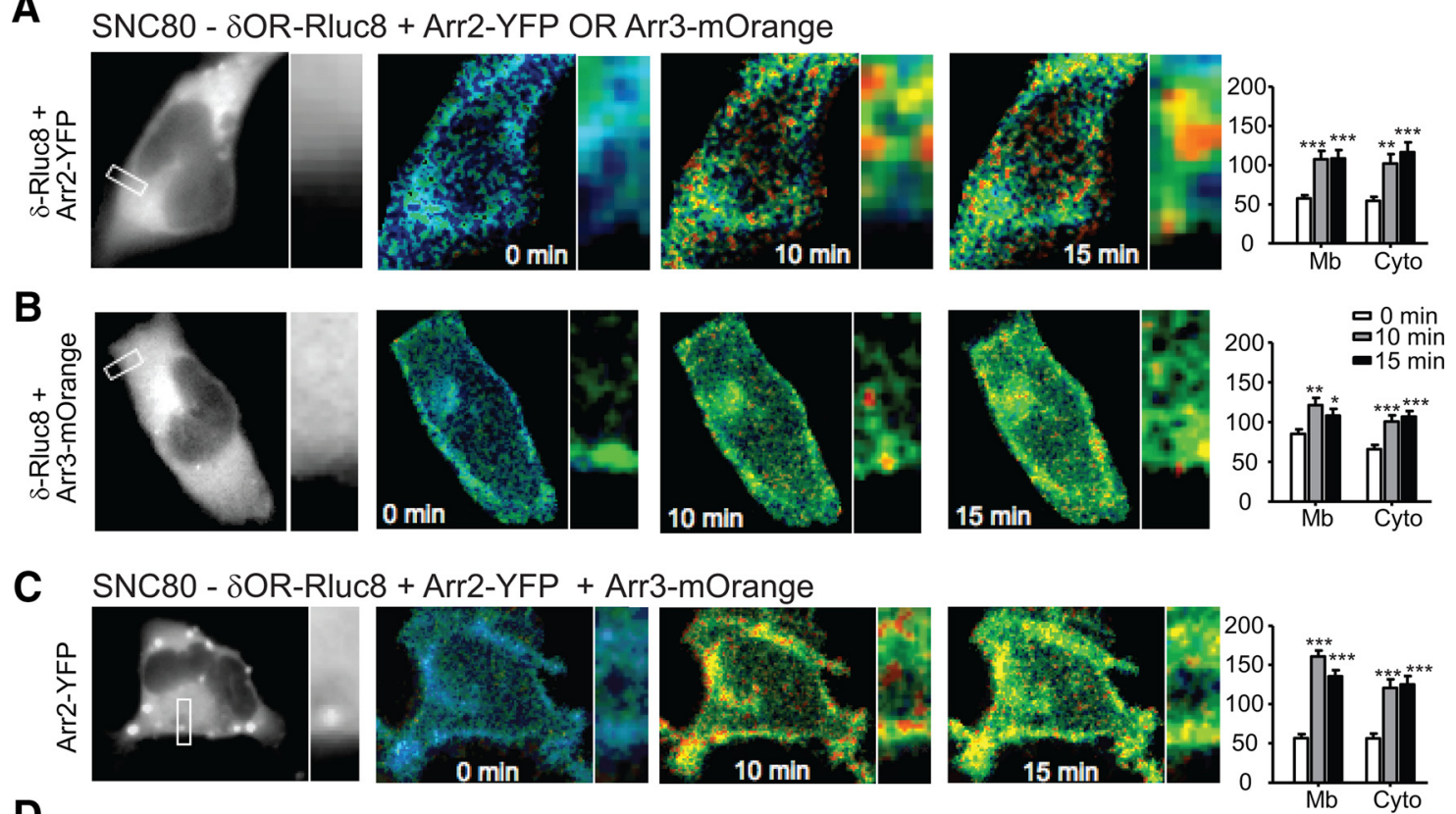

D
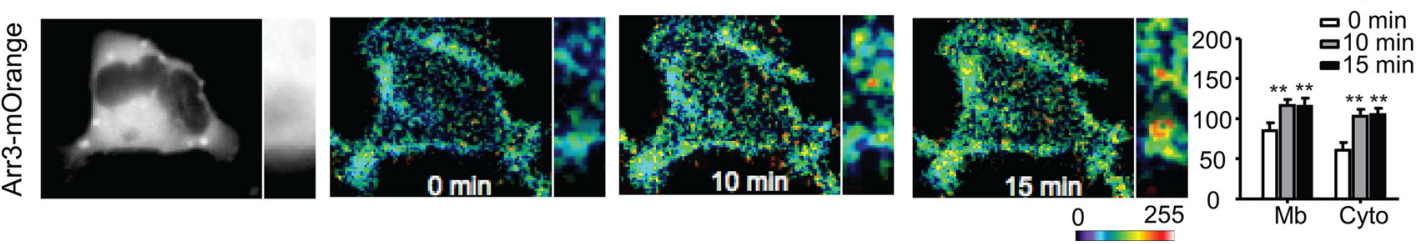

Figure 6. SNC80 causes receptor internalization with both arrestin 2 and 3 . HEK293 cells transfected with $\delta 0 R-R l u c 8$ and Arr2-YFP $(\boldsymbol{A}), \delta 0 \mathrm{R}-\mathrm{Rluc} 8$ and Arr3-m0range (B), or $\delta 0 \mathrm{R}-\mathrm{Rluc} 8$, Arr2-YFP, and Arr2-mOrange $(\boldsymbol{C}, \boldsymbol{D})$. For the three partner-BRET experiment, $\boldsymbol{C}$ shows representative images from the Arr2-YFP channel and $\boldsymbol{D}$ those from the Arr3-m0range channel. Cells were incubated with SNC80 (100 nM) and mean BRET intensity was quantified for the cell membrane (Mb) and the cytoplasm (Cyto) at time 0,10 , and 15 min after SNC80 administration. ${ }^{*} p<0.05,{ }^{* *} p<0.01$, and ${ }^{* * *} p<0.001$, one-way ANOVA with Holm-Sidak post hoc analysis ( $n=3-6$ cells and 7 square regions per subcellular compartment). The high-internalizing agonist SNC80 induced robust internalization with either arrestin 2 or 3.

though the cytosolic interaction observed in the absence of arrestin 3 was attenuated (Fig. $5 B$ vs $D$, Cyto). ARM390 continued to increase the interaction between $\delta \mathrm{OR}-\mathrm{Rluc} 8$ and Arr3-mOrange only at the cell membrane (Fig. $5 E, \mathrm{Mb}$ ). Together, these data indicate that there is a preexisting basal interaction between the delta opioid receptor and arrestin 3 at the cell membrane, which is strengthened by the binding of ARM390. This enhanced membrane interaction appears to protect the delta opioid receptor from intracellular interactions with arrestin 2 .

Finally, as a control, we analyzed BRET interactions among arrestin 2, arrestin 3, and delta opioid receptors after SNC80 administration (Fig. 6). The addition of SNC80 (0.1 $\mu \mathrm{M})$ significantly increased membrane and cytosolic interactions between SOR-Rluc8 and both Arr2-YFP (Fig. 6A) and Arr3-mOrange (Fig. 6B). This was also true when all three proteins were coexpressed (Fig. $6 C, D$ ), results that are consistent with SNC80 being a high-internalizing agonist.

\section{Discussion}

In this study, we found that delta opioid receptor agonists preferentially recruit specific arrestins in a ligand-selective manner (Fig. 7). The high-internalizing agonist SNC80 preferentially recruited arrestin 2 and $\mathrm{KO}$ of arrestin 2 resulted in increased potency and duration of action and decreased acute tolerance to this agonist. In contrast, the low-internalizing agonists preferentially engaged arrestin 3. Surprisingly, $\mathrm{KO}$ of arrestin 3 resulted in gain of acute tolerance to the low-internalizing agonists ARM390 and JNJ20788560, an effect not observed in WT mice. Electrophysiolog- ical recordings from adult DRGs showed that, in the absence of arrestin 3, desensitization rates were unaltered, but resensitization, the recovery from the desensitized state, was markedly delayed. BRET analysis revealed that, in contrast to arrestin 2, delta opioid receptors were pre-engaged with arrestin 3 at the cell membrane and the low-internalizing agonist ARM390 strengthened this association. Overall, these results show a ligand-selective recruitment of arrestins by different delta opioid receptor agonists and reveal a novel endogenous role of arrestin 3 as an inhibitor of acute tolerance and facilitator of receptor resensitization.

We found that the anti-allodynic effects of the high-internalizing agonist SNC80 were modulated by arrestin 2 and not arrestin 3. Our BRET data, along with another BRET-based study (Audet et al., 2012), demonstrate that SNC80 activation recruits both arrestin 2 and 3 isoforms. However, our in vivo results show that, in a chronic pain model, there is a predominance of arrestin 2-regulated behavioral effects by SNC80; and KO of arrestin 2 results in increased drug potency, duration of action, and decreased acute tolerance. In contrast, no change in the antihyperalgesic effect of SNC80 was observed in arrestin 3 KOs. A previous study also showed that $\mathrm{KO}$ of arrestin 2 resulted in increased SNC80-induced hyperlocomotion and cellular functionality (Mittal et al., 2013). In that study, arrestin 2 regulated delta opioid receptor trafficking to the cell membrane and $\mathrm{KO}$ of arrestin 2 resulted in enhanced externalization of receptors in response to SNC80 via a deregulated ROCK/LIMK pathway. The enhancement of agonist-induced externalization, and potentially 


\section{Wildtype}

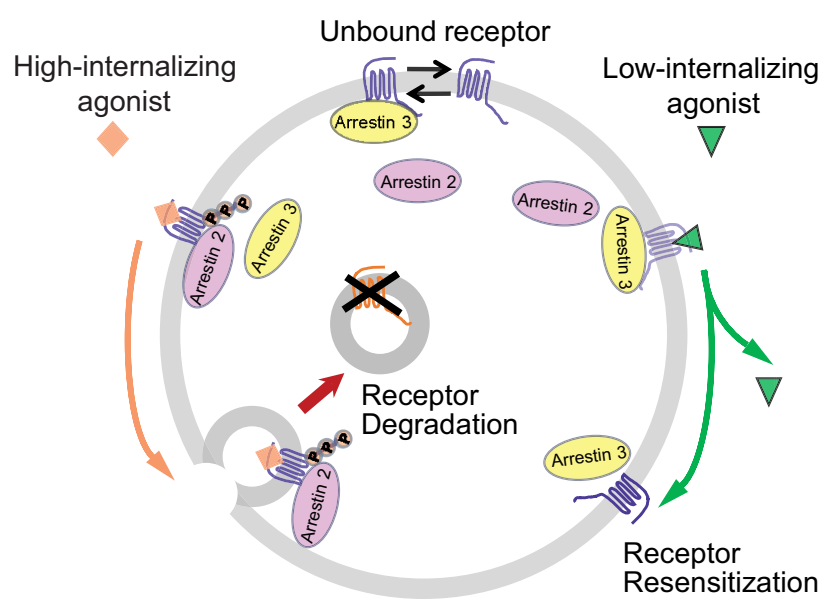

Arrestin $3 \mathrm{KO}$

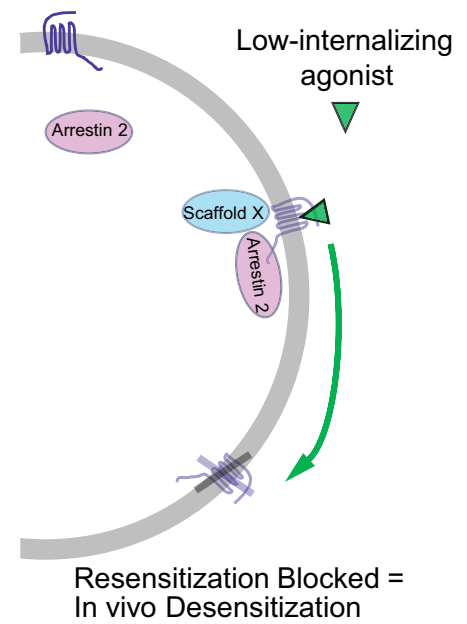

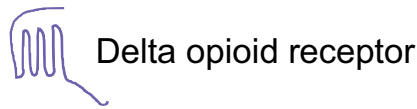

Figure 7. Arrestins are recruited in a ligand-specific manner to the delta opioid receptor. Under basal conditions (no agonist bound), delta opioid receptors are in a pre-engaged complex with arrestin 3 at the cell membrane. High-internalizing agonist such as SNC80 induce substantial receptor phosphorylation, preferentially recruit arrestin 2, and result in receptor internalization and degradation. In contrast, low-internalizing agonists such as ARM390 and JNJ20788560 induce a receptor confirmation that strengthens the engagement between delta opioid receptor and arrestin 3 at the cell membrane and encourages receptor resensitization, thus preventing acute behavioral tolerance. In the absence of arrestin 3, low-internalizing agonists undergo desensitization similarly to WT animals, but we hypothesize that a different receptor complex is formed, perhaps with arrestin 2 or another GPCR modulator, which hinders resensitization. The mechanism underlying arrestin 3-mediated receptor resensitization remains to be elucidated.

altered desensitization/resensitization and trafficking, explain the increased efficacy and lack of tolerance to SNC80 in arrestin 2 KOs.

We were surprised to find that the low-internalizing agonists ARM390 and JNJ20788560 recruited arrestins because neither compound induces robust delta opioid receptor internalization (Pradhan et al., 2009). Furthermore, arrestin $3 \mathrm{KO}$ resulted in a gain of acute tolerance to both low-internalizing agonists, an effect not observed in WT mice (Pradhan et al., 2009; Pradhan et al., 2010). These results are in direct contrast to the findings for mu opioid receptors, in which arrestin 3 KOs exhibit decreased mu opioid receptor desensitization (Mittal et al., 2013) and decreased anti-nociceptive tolerance (Bohn et al., 2000; Bohn et al., 2002) that have been attributed to facilitation of mu receptor resensitization (Dang and Christie, 2012; Williams et al., 2013; Connor et al., 2015). Together, these data suggest that endogenously arrestin 3 attenuates resensitization to mu, yet enhances delta opioid receptor resensitization. We speculate that this converse role of arrestin 3 is orchestrated via the highly divergent C-terminal domains of $\mathrm{mu}$ and delta, which are known to mediate interactions with many regulatory proteins, including arrestins.

Our BRET analysis provides insight on how low-internalizing agonists might result in acute tolerance in arrestin $3 \mathrm{KOs}$. Livecell imaging revealed that, in a naive state, there was a basal engagement between the delta opioid receptor and arrestin 3 at the cell membrane, an interaction not observed with arrestin 2 . This arrestin 3 interaction was strengthened with ARM390 and this enhanced membrane interaction could promote recovery of the delta opioid receptor after binding to low-internalizing agonists. One other recent study also showed that ARM390 could recruit arrestin 3 in a cell-based recruitment assay (Chiang et al., 2015). To better reflect our in vivo acute tolerance experiments, electrophysiological experiments on adult DRGs were performed using longer time points. These studies revealed that, although delta opioid receptors desensitized equally to ARM390 in both arrestin $3 \mathrm{WT}$ and KO DRGs, subsequent resensitization was impaired in arrestin $3 \mathrm{KOs}$. These results indicate that the presence of arrestin 3 is required to facilitate the return of delta opioid receptor functionality after acute exposure to a low-internalizing agonist.

One interpretation of our data is that, in the absence of arrestin 3, the delta opioid receptor is more susceptible to long-term desensitization by other receptor modulators, perhaps including arrestin 2. Results from our BRET experiments indicate that, in the absence of arrestin 3, ARM390 increases the intracellular complexes between the delta receptor and arrestin 2. Interestingly, in coexpression studies, the binding of ARM390 also recruited arrestin 2 to the membrane, but competition with arrestin 3 prevented further interaction. In vivo, we did not observe significant internalization of DOR-eGFP in arrestin $3 \mathrm{KO}$ mice, but this does not exclude the possibility that arrestin 2 mediates a long-duration desensitization at or close to the cell membrane. For example, other modulators of desensitization such as GRKs or calmodulin could have an enhanced role in regulation of ARM390-bound delta opioid receptors in arrestin 3 KOs.

An alternative explanation is that arrestin 3 facilitates recycling after delta opioid receptor binding to low-internalizing agonists. Although ARM390 has not been shown to produce profound receptor internalization, even in time-lapse cellular experiments (Pradhan et al., 2009), there is the possibility that lowinternalizing agonists produce a rapid receptor recycling close to the membrane (Audet et al., 2012; Ong et al., 2015). In this cir- 
cumstance, arrestin 3 could enable a quick replacement of desensitized receptors at the membrane with fully active recycled delta opioid receptors. In vivo, we did not observe significant receptor internalization to ARM390 in arrestin 3 KO-DOR-eGFP mice, but recycling close to the membrane would not be detected at this resolution.

The ligand-specific recruitment of arrestins observed in our studies is likely due to distinct conformational changes induced by high- and low-internalizing delta agonists. Ligand-initiated phosphorylation of the delta opioid receptor is an important step toward receptor desensitization and/or internalization. Phosphorylation of GPCRs at the $\mathrm{C}$ terminus can provide a substrate for high-affinity binding to arrestins. We have shown previously in brain samples that SNC80, but not ARM390, can produce phosphorylation at the serine 363 residue of the delta opioid receptor (Pradhan et al., 2009). Phosphorylation of this residue is a principal event for receptor internalization (Kouhen et al., 2000) and predicts internalization across numerous delta ligands (Bradbury et al., 2009). In addition, in coimmunoprecipitation studies of transfected HEK293 cells, arrestin 2 appears to have a higher affinity for phosphorylated delta opioid receptor compared with arrestin 3 (Zhang et al., 2008; but see Qiu et al., 2007). SNC80 produces receptor phosphorylation, which recruits arrestin 2 and facilitates receptor internalization, corresponding to the traditional role of arrestins as attenuators of GPCR signaling.

Although ARM390 does not phosphorylate the delta opioid receptor at the critical Ser363, it may phosphorylate the receptor at other residues, resulting in increased affinity between the receptor and arrestin 3 at the cell surface. Audet et al. (2012) showed that DPDPE, a high-internalizing delta agonist, induced a distinct conformational change that led to a transient interaction between the delta opioid receptor and arrestin 3 that encouraged rapid receptor recycling. High- and low-internalizing mu opioid receptor agonists have also been shown to encode distinct phosphorylation patterns in which internalization (but not interaction) with arrestins is only initiated after phosphorylation of critical residues (Lau et al., 2011; Doll et al., 2012; Just et al., 2013). Furthermore, phosphorylation-deficient mutants of the $\beta 2$ adrenergic receptor and angiotensin II receptor have also been shown to interact with arrestins in a transient manner (Shukla et al., 2008), also indicating that changes in receptor conformation may be sufficient to increase receptor-arrestin interactions in the absence of internalization. Our data indicate that the delta opioid receptor can adopt different conformational states that affect receptor-arrestin interactions.

Ligand-biased recruitment of different arrestins has been observed for other GPCRs in vitro. For example, the lowinternalizing mu opioid receptor agonist morphine primarily recruits arrestin 3, whereas the high-internalizing agonist DAMGO can recruit either arrestin 2 or 3 (Groer et al., 2011). In addition, endogenous ligands for the C-C chemokine receptor 7 also show differential internalizing properties; and the high-internalizing ligand CCL19 preferentially recruits arrestin 3 over 2, whereas the low-internalizing ligand CCL21 engages neither (Byers et al., 2008). In addition, binding of ATP induces a greater interaction between $\mathrm{P} 2 \mathrm{Y} 2$ receptor and arrestin 2, contrary to UTP, which nonselectively recruits both arrestins (Hoffmann et al., 2008). These studies support the notion that agonists for the same receptor can promote distinct receptor-arrestin complexes.

Our study reveals agonist-specific recruitment of arrestins at the delta opioid receptor. There is a clear distinction behaviorally for arrestin isoforms between the high-internalizing agonist SNC80 and the low-internalizing agonists ARM390 and JNJ20788560. Our results show the behavioral implications of ligand-selective arrestin interactions at the delta opioid receptor and reveal a novel role for arrestin 3 as a facilitator of resensitization and inhibitor of tolerance mechanisms.

\section{References}

Audet N, Galés C, Archer-Lahlou E, Vallières M, Schiller PW, Bouvier M, Pineyro G (2008) Bioluminescence resonance energy transfer assays reveal ligand-specific conformational changes within preformed signaling complexes containing delta-opioid receptors and heterotrimeric $\mathrm{G}$ proteins. J Biol Chem 283:15078-15088. CrossRef Medline

Audet N, Charfi I, Mnie-Filali O, Amraei M, Chabot-Doré AJ, Millecamps M, Stone LS, Pineyro G (2012) Differential association of receptorGbetagamma complexes with beta-arrestin2 determines recycling bias and potential for tolerance of delta opioid receptor agonists. J Neurosci 32:4827-4840. CrossRef Medline

Bohn LM, Gainetdinov RR, Lin FT, Lefkowitz RJ, Caron MG (2000) Muopioid receptor desensitization by beta-arrestin-2 determines morphine tolerance but not dependence. Nature 408:720-723. CrossRef Medline

Bohn LM, Lefkowitz RJ, Caron MG (2002) Differential mechanisms of morphine antinociceptive tolerance revealed in (beta)arrestin-2 knockout mice. J Neurosci 22:10494-10500. Medline

Bradbury FA, Zelnik JC, Traynor JR (2009) G protein independent phosphorylation and internalization of the delta-opioid receptor. J Neurochem 109:1526-1535. CrossRef Medline

Byers MA, Calloway PA, Shannon L, Cunningham HD, Smith S, Li F, Fassold BC, Vines CM (2008) Arrestin 3 mediates endocytosis of CCR7 following ligation of CCL19 but not CCL21. J Immunol 181:4723-4732. CrossRef Medline

Chaplan SR, Bach FW, Pogrel JW, Chung JM, Yaksh TL (1994) Quantitative assessment of tactile allodynia in the rat paw. J Neurosci Methods 53: 55-63. CrossRef Medline

Charfi I, Nagi K, Mnie-Filali O, Thibault D, Balboni G, Schiller PW, Trudeau LE, Pineyro G (2014) Ligand- and cell-dependent determinants of internalization and cAMP modulation by delta opioid receptor (DOR) agonists. Cell Mol Life Sci 71:1529-1546. CrossRef Medline

Charfi I, Audet N, Bagheri Tudashki H, Pineyro G (2015) Identifying ligand-specific signaling within biased responses: focus on delta opioid receptor (Dop) ligands. Br J Pharmacol 172:435-448. Medline

Chiang T, Sansuk K, van Rijn RM (2015) Beta-arrestin 2 dependence of delta opioid receptor agonists is correlated with alcohol intake. Br J Pharmacol. In press

Codd EE, Carson JR, Colburn RW, Stone DJ, Van Besien CR, Zhang SP, Wade PR, Gallantine EL, Meert TF, Molino L, Pullan S, Razler CM, Dax SL, Flores CM (2009) JNJ-20788560 [9-(8-azabicyclo[3.2.1] oct-3-ylidene)9H-xanthene-3-carboxylic acid diethylamide], a selective delta opioid receptor agonist, is a potent and efficacious antihyperalgesic agent that does not produce respiratory depression, pharmacologic tolerance, or physical dependence. J Pharmacol Exp Ther 329:241-251. CrossRef Medline

Connor M, Bagley EE, Chieng BC, Christie MJ (2015) beta-Arrestin-2 knock-out prevents development of cellular mu-opioid receptor tolerance but does not affect opioid-withdrawal-related adaptations in single PAG neurons. Br J Pharmacol 172:492-500. CrossRef Medline

Coulon V, Audet M, Homburger V, Bockaert J, Fagni L, Bouvier M, Perroy J (2008) Subcellular imaging of dynamic protein interactions by bioluminescence resonance energy transfer. Biophys J 94:1001-1009. CrossRef Medline

Dang VC, Christie MJ (2012) Mechanisms of rapid opioid receptor desensitization, resensitization and tolerance in brain neurons. Br J Pharmacol 165:1704-1716. CrossRef Medline

Doll C, Pöll F, Peuker K, Loktev A, Glück L, Schulz S (2012) Deciphering micro-opioid receptor phosphorylation and dephosphorylation in HEK293 cells. Br J Pharmacol 167:1259-1270. CrossRef Medline

Galandrin S, Oligny-Longpré G, Bouvier M (2007) The evasive nature of drug efficacy: implications for drug discovery. Trends Pharmacol Sci 28: 423-430. CrossRef Medline

Gavériaux-RuffC, Nozaki C, Nadal X, Hever XC, Weibel R, Matifas A, Reiss D, Filliol D, Nassar MA, Wood JN, Maldonado R, Kieffer BL (2011) Genetic ablation of delta opioid receptors in nociceptive sensory neurons increases chronic pain and abolishes opioid analgesia. Pain 152:1238-1248. CrossRef Medline

Gendron L, Mittal N, Beaudry H, Walwyn W (2015) Recent advances on the 
$\delta$ opioid receptor: from trafficking to function. Br J Pharmacol 172:403419. Medline

Groer CE, Schmid CL, Jaeger AM, Bohn LM (2011) Agonist-directed interactions with specific beta-arrestins determine mu-opioid receptor trafficking, ubiquitination, and dephosphorylation. J Biol Chem 286:31731-31741. CrossRef Medline

Hoffmann C, Ziegler N, Reiner S, Krasel C, Lohse MJ (2008) Agonistselective, receptor-specific interaction of human $\mathrm{P} 2 \mathrm{Y}$ receptors with betaarrestin-1 and -2. J Biol Chem 283:30933-30941. CrossRef Medline

Hong MH, Xu C, Wang YJ, Ji JL, Tao YM, Xu XJ, Chen J, Xie X, Chi ZQ, Liu JG (2009) Role of Src in ligand-specific regulation of delta-opioid receptor desensitization and internalization. J Neurochem 108:102-114. CrossRef Medline

Just S, Illing S, Trester-Zedlitz M, Lau EK, Kotowski SJ, Miess E, Mann A, Doll C, Trinidad JC, Burlingame AL, von Zastrow M, Schulz S (2013) Differentiation of opioid drug effects by hierarchical multi-site phosphorylation. Mol Pharmacol 83:633-639. CrossRef Medline

Kenakin T (2003) Ligand-selective receptor conformations revisited: the promise and the problem. Trends Pharmacol Sci 24:346-354. CrossRef Medline

Kenakin TP (2012) Biased signalling and allosteric machines: new vistas and challenges for drug discovery. Br J Pharmacol 165:1659-1669. CrossRef Medline

Kouhen OM, Wang G, Solberg J, Erickson LJ, Law PY, Loh HH (2000) Hierarchical phosphorylation of delta-opioid receptor regulates agonistinduced receptor desensitization and internalization. J Biol Chem 275: 36659-36664. CrossRef Medline

Lagerström MC, Schiöth HB (2008) Structural diversity of G proteincoupled receptors and significance for drug discovery. Nat Rev Drug Discov 7:339-357. CrossRef Medline

Lau EK, Trester-Zedlitz M, Trinidad JC, Kotowski SJ, Krutchinsky AN, Burlingame AL, von Zastrow M (2011) Quantitative encoding of the effect of a partial agonist on individual opioid receptors by multisite phosphorylation and threshold detection. Sci Signal 4:ra52. Medline

Law PY, Kouhen OM, Solberg J, Wang W, Erickson LJ, Loh HH (2000) Deltorphin II-induced rapid desensitization of delta-opioid receptor requires both phosphorylation and internalization of the receptor. J Biol Chem 275:32057-32065. CrossRef Medline

Lowe JD, Celver JP, Gurevich VV, Chavkin C (2002) mu-Opioid receptors desensitize less rapidly than delta-opioid receptors due to less efficient activation of arrestin. J Biol Chem 277:15729-15735. CrossRef Medline

Luttrell LM (2014) Minireview: More than just a hammer: ligand "bias" and pharmaceutical discovery. Mol Endocrinol 28:281-294. CrossRef Medline

Mittal N, Roberts K, Pal K, Bentolila LA, Fultz E, Minasyan A, Cahill C, Pradhan A, Conner D, DeFea K, Evans C, Walwyn W (2013) Select G-protein-coupled receptors modulate agonist-induced signaling via a ROCK, LIMK, and beta-arrestin 1 pathway. Cell Rep 5:1010-1021. CrossRef Medline

Ong EW, Xue L, Olmstead MC, Cahill CM (2015) Prolonged morphine treatment alters delta opioid receptor post-internalization trafficking. $\mathrm{Br}$ J Pharmacol 172:615-629. CrossRef Medline

Perroy J (2010) Subcellular dynamic imaging of protein-protein interactions in live cells by bioluminescence resonance energy transfer. Methods Mol Biol 591:325-333. CrossRef Medline

Pierce KL, Premont RT, Lefkowitz RJ (2002) Seven-transmembrane receptors. Nat Rev Mol Cell Biol 3:639-650. CrossRef Medline

Pradhan AA, Becker JA, Scherrer G, Tryoen-Toth P, Filliol D, Matifas A, Massotte D, Gavériaux-Ruff C, Kieffer BL (2009) In vivo delta opioid receptor internalization controls behavioral effects of agonists. PLoS One 4:e5425. CrossRef Medline

Pradhan AA, Walwyn W, Nozaki C, Filliol D, Erbs E, Matifas A, Evans C, Kieffer BL (2010) Ligand-directed trafficking of the delta-opioid receptor in vivo: two paths toward analgesic tolerance. J Neurosci 30:1645916468. CrossRef Medline
Pradhan AA, Befort K, Nozaki C, Gavériaux-Ruff C, Kieffer BL (2011) The delta opioid receptor: an evolving target for the treatment of brain disorders. Trends Pharmacol Sci 32:581-590. CrossRef Medline

Pradhan AA, Smith ML, Kieffer BL, Evans CJ (2012) Ligand-directed signalling within the opioid receptor family. Br J Pharmacol 167:960-969. CrossRef Medline

Qiu Y, Loh HH, Law PY (2007) Phosphorylation of the delta-opioid receptor regulates its beta-arrestins selectivity and subsequent receptor internalization and adenylyl cyclase desensitization. J Biol Chem 282:22315-22323. CrossRef Medline

Raehal KM, Bohn LM (2011) The role of beta-arrestin2 in the severity of antinociceptive tolerance and physical dependence induced by different opioid pain therapeutics. Neuropharmacology 60:58-65. CrossRef Medline

Rajagopal S, Rajagopal K, Lefkowitz RJ (2010) Teaching old receptors new tricks: biasing seven-transmembrane receptors. Nat Rev Drug Discov 9:373-386. CrossRef Medline

Reiter E, Ahn S, Shukla AK, Lefkowitz RJ (2012) Molecular mechanism of beta-arrestin-biased agonism at seven-transmembrane receptors. Annu Rev Pharmacol Toxicol 52:179-197. CrossRef Medline

Richard-Lalonde M, Nagi K, Audet N, Sleno R, Amraei M, Hogue M, Balboni G, Schiller PW, Bouvier M, Hébert TE, Pineyro G (2013) Conformational dynamics of Kir3.1/Kir3.2 channel activation via delta-opioid receptors. Mol Pharmacol 83:416-428. CrossRef Medline

Scherrer G, Tryoen-Tóth P, Filliol D, Matifas A, Laustriat D, Cao YQ, Basbaum AI, Dierich A, Vonesh JL, Gavériaux-Ruff C, Kieffer BL (2006) Knockin mice expressing fluorescent delta-opioid receptors uncover G protein-coupled receptor dynamics in vivo. Proc Natl Acad Sci U S A 103:9691-9696. CrossRef Medline

Shenoy SK (2014) Arrestin interaction with E3 ubiquitin ligases and deubiquitinases: functional and therapeutic implications. Handb Exp Pharmacol 219:187-203. CrossRef Medline

Shenoy SK, Lefkowitz RJ (2011) beta-Arrestin-mediated receptor trafficking and signal transduction. Trends Pharmacol Sci 32:521-533. CrossRef Medline

Shukla AK, Violin JD, Whalen EJ, Gesty-Palmer D, Shenoy SK, Lefkowitz RJ (2008) Distinct conformational changes in beta-arrestin report biased agonism at seven-transmembrane receptors. Proc Natl Acad Sci U S A 105:9988-9993. CrossRef Medline

Tudashki HB, Robertson DN, Schiller PW, Pineyro G (2014) Endocytic profiles of delta-opioid receptor ligands determine the duration of rapid but not sustained cAMP responses. Mol Pharmacol 85:148-161. Medline

van Rijn RM, Defriel JN, Whistler JL (2013) Pharmacological traits of delta opioid receptors: pitfalls or opportunities? Psychopharmacology 228: 1-18. CrossRef Medline

Walwyn W, Maidment NT, Sanders M, Evans CJ, Kieffer BL, Hales TG (2005) Induction of delta opioid receptor function by up-regulation of membrane receptors in mouse primary afferent neurons. Mol Pharmacol 68:1688-1698. Medline

Williams JT, Ingram SL, Henderson G, Chavkin C, von Zastrow M, Schulz S, Koch T, Evans CJ, Christie MJ (2013) Regulation of mu-opioid receptors: desensitization, phosphorylation, internalization, and tolerance. Pharmacol Rev 65:223-254. CrossRef Medline

Zhang B, Horvath S (2005) A general framework for weighted gene coexpression network analysis. Stat Appl Genet Mol Biol 4:Article17. Medline

Zhang X, Wang F, Chen X, Li J, Xiang B, Zhang YQ, Li BM, Ma L (2005) Beta-arrestin1 and beta-arrestin2 are differentially required for phosphorylation-dependent and -independent internalization of delta-opioid receptors. J Neurochem 95:169-178. CrossRef Medline

Zhang X, Wang F, Chen X, Chen Y, Ma L (2008) Post-endocytic fates of delta-opioid receptor are regulated by GRK2-mediated receptor phosphorylation and distinct beta-arrestin isoforms. J Neurochem 106: 781-792. CrossRef Medline 